'Gender ratios in library management ('directorship') roles in New Zealand public and tertiary libraries'

by

\title{
Gareth Shute
}

Submitted to the School of Information Management,

Victoria University of Wellington

in partial fulfilment of the requirements for the degree of

Master of Information Studies 


\section{Abstract}

Research problem: This study looked at the percentage of female managers in charge of library systems within New Zealand between 1980 and 2013 to see if their gender balance matched the wider library workforce (which has upwards of $80 \%$ female staff).

Methodology: Directories of public libraries were examined and the gender of each library manager was noted.

Results: The overall figure for library managers was found to be around $80 \%$, with a slight improvement over the period examined. However, when public libraries were divided by size, the results for the 1980s showed that large libraries had fewer female managers than the overall library workforce, while small libraries had a larger percentage. This difference was shown to decrease over the period studied, until both large and small libraries had around $80 \%$ female staff. A similar result was shown in preliminary data sourced from New South Wales (Australia), which suggested that this trend also occurs overseas. The New Zealand data also considered tertiary institutions. At the beginning of the study, only one out of six university library systems was managed by a woman, while in the most recent year seven out of ten managers were female. In contrast, there was found to be a high percentage of female managers in charge of polytechs over this same time. Implications: These results suggest that a gender bias existed within some sectors of librarianship (within large public libraries and university libraries) at the beginning of the study period, but that this bias has largely disappeared in recent years.

Keywords: female, managers, public libraries, management, university, polytech. 


\section{Table of Contents}

$\begin{array}{ll}\text { Abstract } & 2\end{array}$

$\begin{array}{ll}\text { Introduction } & 4\end{array}$

$\begin{array}{ll}\text { Methodology } & 14\end{array}$

$\begin{array}{ll}\text { Results } & 16\end{array}$

$\begin{array}{ll}\text { Discussion } & 21\end{array}$

$\begin{array}{ll}\text { Conclusion } & 27\end{array}$ 


\section{Introduction}

Librarianship is a profession that is largely staffed by women. The most recent available census results from Statistics NZ (2006) showed that $86 \%$ of people who listed the job code 'Librarian' or 'Library Assistant' were female. This is backed up by an extensive survey conducted by the New Zealand Library Association Inc. (LIANZA, 2010) on its members. Amongst the survey respondents, $84 \%$ were female, though this figure reduced to $79 \%$ for those who reported working at university libraries. Male respondents also reported that their income was $4 \%$ higher than their female colleagues.

A similar figure of $86 \%$ female staff was also found in an extensive study of public libraries in Australia (Australian Bureau of Statistics, 2004) and this matches up with earlier findings from this country (over a decade earlier, the figure of $85 \%$ was reported by Currie, 1992). Meanwhile, in the US, census data showed a figure of $83 \%$ female staff in libraries (Beveridge, Weber, and Beveridge, 2009).

Looking over these various statistics from across the world, we would expect that library management to be made up of at least $80 \%$ women in order for it to match-up with the gender ratio within the general workforce. Even with the variation between the figures from different countries, it seems justifiable to say that unless a benchmark of $80 \%$ can be reached then there is a gender imbalance within the management of libraries.

A number of researchers have investigated whether such a gender imbalance can be found within libraries. In one of the most comprehensive studies that has been conducted, Fisher (1997) found that the overall gender ratio of managers in public and university libraries did roughly match the wider population. However, the percentage of women managers decreased as the size of the library increased. Fisher's results seem to reflect the existence of a 'glass ceiling' effect, whereby women find it hard to move up the management hierarchy to take charge of larger libraries. Certainly it is true that other researchers have argued that a glass ceiling exists within the library profession (Jones and Oppenheim, 2002).

Moran, Leonard, and Zellers (2009) updated Fisher's work on academic libraries by examining the libraries contained within some of the most high prestige universities in the US. Unfortunately their research didn't take into account the size of the library involved, though they did look how the situation changed over time. They found a marked increase in the ratio of female directors over time (reaching from $13.5 \%$ to $67 \%$ in 2009 ) and their findings were supported by a similar, but smaller study by Deyrup (2004). 
The current research sought to compare the situation in New Zealand to the studies mentioned above, so it was both a longitudinal study and, where possible, it also attempted to take into account the size of the libraries involved. In particular, it looked at the equivalent positions to 'director' in New Zealand public libraries and tertiary institutions. Within New Zealand the role in question is usually referred to as the 'library manager', so this is the term that will be used here ('branch manager' will be used to describe those in charge of only a single branch). The ratio of females and males in these roles was assessed over time, using data from the years: 1980, 1985, 1990, 1995, 2000, 2005 , 2010, and 2013. This information was gathered from a number of publicly available sources, both online and in print publications (see below). This figure was then compared to the $80 \%$ benchmark figure discussed above.

There was also an attempt to compare the results from New Zealand to data from the Australian state of New South Wales (NSW). Fortunately NSW has a similar directory of libraries that lists the manager of each library system. It is also the largest state in Australia, so it was hoped that it would provide some indication of the situation in this country generally and possibly give an indication of the greater applicability of the current findings in an international context.

The results of the current study are important because they provide information on whether the management role of women in New Zealand libraries is an issue that needs to be addressed. If there is a mismatch in the ratios of females/males at the management level when compared to the general cohort then it might suggest a gender bias is in effect and possible mechanisms behind this effect (e.g., the glass ceiling and/or glass escalator) are discussed at the end of the 'other research' section below. This research will also feed into the wider research on gender equality, especially within a New Zealand context.

\section{Literature Review.}

In order to fill in more of the background of the current study, it is worth undertaking a closer examination of the original studies from the U.S that laid the groundwork for this research. We will then turn to other international research in this area and examine some of the theories that have been used to explain the gender bias previously found in library management. Finally, research from within New Zealand will be examined to see what this might suggest about the local situation. 


\section{A Closer Examination of Fisher's Findings.}

As mentioned above, Fisher's main aim was to see whether the ratio of female library managers matched the gender balance of $80 \%$ women within the overall workforce of librarians. Fisher noted that many previous investigations had found a far lower percentage of women in library management, but he argued that many of these studies had been hampered by small sample sizes and tended to look only at large public and academic libraries. In order to rectify this problem, Fisher based his research on the main US library directories from 1994, which listed all of the public and academic libraries throughout the country (including the smaller libraries and special libraries). His results showed that $77 \%$ of the managers were female. However, when he looked at more closely at his data, a more complicated picture emerged.

Examining the public library results, he found that the percentage of female managers was even higher (86\%). Yet, when he removed the branch managers from his figures and only looked at the directors (who managed a whole library system), the percentage dropped to $73 \%$. When he further divided these directors into those serving different sizes of library system, he found that smaller library systems (serving 15,000 people or fewer) had a very high percentage of female directors (93\%), but this percentage decreased as the size of the library system increased, as follows:

- Medium Libraries (serving 15,001-75,000) had 72\% female directors

- Medium-Large Libraries (serving 75,000-200,000) had 55\% female directors

- Large Libraries (serving 200,001 or more) had 47\% female directors.

These results clearly show that as the library system increases in size, there seems to be a corresponding fall in the number of female directors.

Fisher also looked at the situation within academic libraries and found a far lower overall total (56\%). Once again, he also looked at the directorship level of management and found a trend relating library size to the ratio of female directors:

- Large Libraries (holding over 700,001 items) had 36\% female directors

- Medium-Large Libraries (holding 100,001-700,000 items) had 42\% female directors

- Medium Libraries (holding 10,001-100,000 items) had 60\% female directors

- Small Libraries (holding 10,000 or fewer items) had 74\% female directors 
Fisher admitted that his findings were hampered by two issues: firstly, some of the directory listings were unusable since they didn't clearly suggest the gender of the manager or simply didn't list one at all (though Fisher doesn't give an indication of how many results were effected); and secondly his approach could only tease out managers that were running a 'physically separate' unit, so many middle-management positions may have been excluded.

Fisher's findings are certainly striking, though his work on public libraries does not seem to have been repeated. However, there have been a couple of other studies into the situation within academic libraries and we will examine these next.

\section{A Closer Examination of Moran, Leonard, and Zellers' Findings.}

Moran, Leonard, and Zellers (2009) wanted to replicate a study conducted by Moran in 1982, which used the listings in American Library Directory to ascertain the ratio of female/male directors in charge of academic libraries. Their study looked at 99 members of the Association of Research Libraries (ARL) and 112 Carnegie Classification 'Liberal Arts l' libraries, proposing that these institutions were 'selected because they represent institutions where women were most likely to encounter a glass ceiling' (pg. 221), though no explanation of this reasoning was given.

Moran, Leonard, and Zellers analysed the distribution of men and women in the three tiers of administration. They found that women made up $67 \%$ of academic library managers in 2004 (across these three tiers) and argued that this was a vast improvement when compared to the figure of $13.5 \%$ that Moran found in her original 1982 study and a solid improvement on her finding in a subsequent study in 1994, which uncovered a figure of $39.4 \%$. It is worth noting that this 1994 figure seems markedly different from the $56 \%$ figure that Fisher's (1997) research came up with using data from the same year and it therefore seems that the variety of library may have caused the difference in these results.

Moran et al argued that their 2004 finding of $67 \%$ female managers was a very positive result given that previous research has shown that $70 \%$ of 'credentialed' staff within academic libraries are women (Davis and Hall, 2007, pg. 20) and it therefore seems as if they may have a slightly lower percentage of women than the wider library workforce (though in New Zealand, the best estimate would be $79 \%$ female university library staff, LIANZA, 2010). One explanation could be that men seek library credentials more readily and that we might find a similar ratio of men/women in the wider workforce if we only looked at those with library-related qualifications. If this was the case, it would suggest that 
the issue is with the proportion of women who seek library credentials rather than gender issues in the employment of managers. However, Owens (2009) has found that the number of female students in library school programs in the US is around $80 \%$, though he did find they were less inclined towards advancement (see the 'Other studies' section below for more information).

Despite the positive trend found by Moran, Leonard, and Zellers, it is important to note that their figures for the directorship level of management fell below their overall figure of $67 \%$ - the 'Liberal Arts l' institutions found only $50.9 \%$ of library directors, while the ARL libraries had $60.6 \%$. Therefore this remained one area where a gender bias was still clearly in existence. It would be interesting to know whether this result could be attributed to a difference in size between the ARL and Liberal Arts I institution libraries, which might show a similar effect to that found by Fisher, but Moran et al do not supply this information. In any case, these results clearly show that elite institutions still have a gender imbalance at the level of library directorship.

\section{A Closer Examination of Deyrup's Findings.}

Deyrup (2004) also investigated gender ratios within academic library management, but took an even more limited focus than Moran - examining only Carnegie doctoral research/extensive institutional libraries, because she wanted to make the range of her study more manageable (she also argued that these institutions are broadly representative of top-tier public and private universities). She found women comprised $55 \%$ of top administrators and noted that this matched up closely with a study conducted by ALA's Office for Research and Statistics, which showed that women now constitute $57 \%$ of all college and university library directors. She pointed out that this was an improvement compared to a similar study in 1972 , which found that only $4.6 \%$ of library directors were female. On the positive side, Deyrup also found that female directors of academic libraries received a similar pay-rate to male directors (on average $92 \%$ of average male salary, though one might remark that this is still a marked difference).

Along with the two studies cited above, Deyrup's research suggests that there was an ongoing gender imbalance within the management of university libraries (when compared to overall library workforce), though this situation has improved over time. The size of the libraries involved was not discussed by Deyrup, so it is difficult to perceive whether this may have been a contributing factor to the low percentage found. 
Other Studies of the Male/Female Ratio within Libraries.

A number of reasons might be given for why women in libraries have been found not to progress to top management roles (i.e., those at larger libraries) at the rate expected from the general population. Often the idea of a 'glass ceiling' is invoked, which is an invisible barrier that keeps women from upper management. Simon (1996) argued that there are two main ways in which a glass ceiling might come about:

1. 'current organizational cultures act as barriers to women's equal participation.'

2. 'women lack the necessary characteristics to pursue managerial careers.'

(Simon, pg. 5)

Simon sent out 500 questionnaires to library workers in Queensland (Australia) and received 211 responses. Her results suggested that both of the aforementioned causes were in effect, thereby creating a 'double-glazed' glass ceiling that women saw as limiting their career options.

The first effect (a limiting organizational culture) is usually seen as a result of gender stereotyping that stops women being seen as suitable managers. Often the 'glass ceiling' theory is paired with the corresponding theory of the 'glass escalator' that helps men progress into management within female-dominated professions. The phrase 'glass ceiling' emerged in the 1980s as a description of the intangible barriers that stopped women from being promoted into management positions. Usually this effect was attributed to structural obstacles and the existing preponderance of male managers, who were biased towards promoting other men into management positions (Freeman, 1990). A recent study by the US Department of Labor (2011) found continuing evidence for a glass ceiling effect within US businesses. They proposed that the effect was caused by a combination of $(A)$ societal barriers, $(B)$ adequate supply of qualified staff, and (C) unconscious stereotyping. Within libraries, there is a far higher proportion of female workers and the work of Owens (2009) showed that there is a similarly high number of female graduates from library programs, so we might expect this would mitigate the issue of supply (B).

Given that libraries have a higher proportion of female workers, it seems possible that the effect of stereotyping might also be lessened. More specifically, the existence of a mainly female workforce would mean that it was more difficult to avoid hiring women into management positions and that once there were a certain amount of female managers, 
the effect would gradually diminish. Williams was interested in looking at this issue. Her findings led her to posit that there was a 'glass escalator' that assisted men in achieving promotions even within female-dominated professions.

The research that led Williams to this conclusion was a set of interviews she conducted with male and female workers in four professions strongly dominated by women: elementary school teaching, librarianship, nursing, and social work. She conducted indepth interviews with 99 men and women in these professions, across four large urban centres in the US. Her results showed that men who are working in female dominated professions are often subjected to positive discrimination from within the workplace by being singled out as potential managers by their superiors, because of their gender.

This result led her to create the concept of a 'glass escalator' which exists for men in female-dominated professions - in effect, elements of the work environment that make it easier for them to achieve career advancement and salary increases.

Williams also found that men in female-dominated professions received negative discrimination from outside the workplace. The result is that men feel themselves pushed towards more typically gendered jobs within the profession (e.g. management), which are seen as more socially acceptable from the outside perspective. If they can't move into what are seen as more gender-appropriate roles then men often feel compelled to leave the profession. The glass escalator is therefore the flipside of the glass ceiling and provides another reason why men might advance disproportionately into management positions even within a profession with a high percentage of female workers.

Moving on to Simon's second cause of gender imbalance, we find that the main characteristic that is often seen to limit women's careers is their role in childrearing. It is still more common for women than men to take time off to raise children and this necessitates time away from focusing on their careers. Jones and Oppenheim (2002) found that this was a major issue that inhibited the progression of women within the library profession. They sent out a questionnaire to members of the UK library association and had 187 respondents in all (151 women and 36 men). They found that many women believed that taking a break from work to have children had adversely affected their career. A number of them also pointed to the fact that they had moved house when their husband had started a new job in a different area and this had also caused a break in the woman's own career.

In the US, this subject was examined by a smaller study undertaken by Zemon and Bahr (2005). They sent out surveys to 539 directors of academic libraries and received 347 usable responses. Their results showed that very few of the directors who had 
children found that there was any negative impact on their careers. However, one might argue that this result ignores the fact that many women with management potential may have been hindered from becoming directors by the interruption caused by having children, while the survey only looked at those who had successfully navigated this issue and therefore were less likely to see it as a problem.

Jones and Oppenheim argued that the willingness of women to take time off to raise children or to move location for their partner's job, was reflective of a general difference between male and female library workers in the amount of emphasis they placed upon their own career achievements. For example, women in the survey rated 'job satisfaction' more highly than the men, while the men had a stronger interest than the women in having 'a good salary' and gaining a high 'level of responsibility.' This suggests that women have less drive toward management roles (when compared to men).

A similar conclusion might be drawn from the research of Owens (2009), who surveyed recent graduates from the five LIS graduate-programs in North Carolina to examine how this group differed from the wider workforce. This study found that the proportion of female graduates from this program (82\%) matched up well with the gender bias found in the general library workforce. The survey asked graduates why they had chosen to study librarianship. It found that women tended to value intrinsic elements of the profession (what the job entails), rather than external factors (such as availability of jobs, salary, and career options). Therefore the female graduates were more likely to report agreement with the following statements than their male peers: 'always wanted to be a librarian,' 'it seemed like a good fit for my interests,' 'like working with computers,' 'like working with people,' and 'wanted a job where I could make a difference.' The only external factor that influenced female graduates was that they reported being influenced by the idea that 'an LIS career fits with my family responsibilities.'

Most importantly for our investigation is that women were less likely than men to report 'good opportunities for advancement' as being 'very important.' Therefore women may be less likely to push themselves forward for management roles within libraries, since career advancement is not one of their goals from the start.

Taking these studies as a whole, it seems as if the emphasis of the research into the glass ceiling has changed over the last two decades. The study mentioned above by Jones and Oppenheim (2002) did also look at whether respondents found any evidence of gender stereotyping in their workplace, but this seemed to have far less effect than childrearing and moving geographical location. This contrasts with the work of Simon (1996), who found both gender stereotyping and the specific characteristics of women worked 
together to limit their careers. Perhaps this suggests that the double-glazed glass ceiling has reduced to a single-glazed glass ceiling over this period?

Alternatively, the difference could be attributed to the fact that Simon conducted her research in Australia (rather than the UK). Simon did find some areas in which the gender bias had already come in line with the general population of library workers - she mentions that in Queensland (where she did her study), six out of the seven universities had female managers in charge of their library systems.

Elsewhere in Australia, there have been other signs of a gender bias in the workplace. In one case the bias went against the entire library profession. In 2002, librarians in New South Wales lobbied their local government, because they believed that their pay-rates were unjustly being held at a lower level than comparable jobs and they argued that the reason for this bias was due to librarianship being a profession that had a high percentage of female staff. The government eventually agreed with this proposal and ruled that librarians should be given a pay increase of up to $26 \%$ (NSW Department of Premier and Cabinet, 2002).

There was not scope within the current study to undertake in-depth research into the situation in Australia as a whole, but it was hoped that by looking at data from public libraries in New South Wales (Australia's largest state), it might be possible to get some sense of whether the situation in Australia is similar to New Zealand.

\section{The Situation In New Zealand.}

It is worthwhile to look at the general state of women's employment in New Zealand, before we narrow in to focus on female-dominated professions. Recent research by Grant Thornton Limited (2013) found that 'the percentage of women in senior management positions throughout New Zealand's businesses has stalled at 28\%,' (down from $32 \%$ women in senior management positions in 2011).

This is backed up by the last major study of women in the workplace conducted by the Statistics New Zealand (2006), which found that on average women still earned only $58 \%$ of the average male income (a percentage which hasn't changed since 1991). This result gives an indication that New Zealand is certainly not an exception when it comes to gender inequality in the workplace.

Given that libraries have a high proportion of female staff, it is worth examining other professions with this characteristic. If we examine the female-dominated profession of teaching, we can see that there is clear evidence of a difference in the ratio of males and 
females at a management level. The National Equal Opportunities Network (2012) undertook a census of women in the workplace in New Zealand and found that in the profession of teaching there were $72 \%$ women, but only $42 \%$ women principals. A similar result was recently found in New Zealand newspaper journalism. A PhD dissertation by Cathy Strong (2011) showed that while the majority of journalists are female, few women make it to top levels in the industry. These examples from teaching and journalism provide an initial indication that there may also be a gender bias in management within other female-dominated professions within New Zealand.

Turning to the case of libraries, we find that the situation is less clear from the minimal research that has been conducted up to this point. Harley (2011) conducted a preliminary study into whether the glass escalator theory might be applicable to libraries in New Zealand. He interviewed six men who were either managers or senior librarians (i.e. librarians who carried out management roles, but in support of an overall team leader). He found that none of these interviewees saw themselves as having been promoted due to their gender. However, upon reflection, they were all able to recall situations in which their gender may have put them at an advantage (though Harley suggested that this may have been due to the subjects trying to fit their experience to the theory he had presented, rather than being a true reflection of their overall experience). Nonetheless, it could be possible that the glass escalator was still helping these men achieve their work position, even if they were not aware of it, especially since the subjects did report achieving job positions where they feel inadequate to carry out the work that was required. This may provide some indication that male staff are being promoted beyond their capability (though it might equally reflect that many workers are uncomfortable when they first take up a new position). In general, Harley admitted that his results were inconclusive and he put this down to his small sample size.

One piece of evidence against the idea that there is a gender bias within library management was provided by Helen Hennessey, who is the Executive Director of The Association of Public Library Managers Incorporated. She has noted that their membership consists of 42 women and 11 men (Hennessey, personal communication, March 18, 2013), which would mean that there are $79 \%$ female managers that belong to this group.

One further point is worth making about the New Zealand case before moving on. The most relevant data from the latest census by Statistics New Zealand (2006) is that $86 \%$ of people who listed the job code 'Librarian' (224611) or 'Library Assistant' (599711) were female (as mentioned above). However, there was also a job code of 'Archivist' (224211), which covered a far smaller category of respondents (there were 366 Archivists, 
4299 Librarians and 2346 Library Assistants). Interestingly, the respondents who listed themselves as Archivists were 50.8\% female, meaning that this job type was almost evenly split between the sexes. This suggests that libraries which exist primarily as archives might give us quite different results from these other libraries.

\section{Research Questions.}

The current study addressed the following questions:

1. Is the gender ratio of management in NZ libraries similar to the gender ratio in the profession as a whole?

2. Has the gender ratio of management in NZ libraries changed over time?

3. Do these issues differ between university libraries, polytechs, and teachers colleges?

4. Has the gender ratio of management in NZ public libraries changed over time and is it dependent on the size of library?

5. How does the situation in New Zealand compare to that found in previous overseas studies or available Australian data?

\section{Methodology}

The current study took a similar approach to Fisher (1997), but focused on New Zealand public libraries and tertiary institutions throughout the country. It also looked a public libraries in New South Wales (Australia) to provide a point of comparison. The New Zealand data focused on the library manager of each library system, as listed in the following sources:

- The National Library's online Directory of New Zealand Libraries (National Library of New Zealand, 2010, 2013)

- New Zealand Library Symbols (National Library of New Zealand, 1995, 2000, 2005)

- Who's Who in New Zealand Libraries (New Zealand Library Association 1980, 1985, 1990)

These publications list each of the library systems within New Zealand and give the name of the overall library manager (or librarian-in-charge) of each of them. This level of 
management is a similar to the 'directorship' level that was studied by all three of the studies from the US mentioned above and should therefore provide a direct point of comparison.

Aside from the last year studied, there were 70 public library systems in New Zealand. Almost all of these library systems related directly to a specific local council, except for two councils that share their library systems (Central Otago and Queenstown Lakes). A separate category of research libraries was also created, which looked at libraries who held primarily reference items that weren't for loan.

If no entry was given for a particular library then an effort was made to find this information by searching on the Internet (an approach that worked more effectively for more recent years, since the information was more likely to be online). If no information could be found, then the library was excluded from the count for that year. In two cases, only an acting manager was listed and these were nonetheless included in the final count.

Three sets of tertiary institutions were also examined - universities, polytechs, and teachers colleges. These results were then added to the public and research library data above to give an overall figure, in order to give an indication of the situation within the library profession as a whole.

This study also took a longitudinal approach in order to examine whether there has been any noticeable change within the profession over time. In particular, the research looks at the years: 1980, 1985, 1990, 1995, 2000, 2005, 2010, and 2013. It was decided that this range of dates would provide a good spread of results and was roughly equivalent to the time periods examined by the longitudinal studies of Moran et al and Deyrup.

Fisher's finding that the ratio of female managers increases with the size of the public library in question was examined by dividing the libraries into large and small library systems according to the population that their council serves. This was done by using the most recent census data (Statistics New Zealand, 2006) and finding population figures for each of the council areas (though, since Central Otago and Queenstown Lakes share their library systems, their population figures were combined). This set of 70 libraries was then divided in half, thus creating a separate set of 35 'large' and 35 'small' libraries. The cut-off for large libraries was a population of over 39,000 served. There was also an effort made to check that the ranking of council sizes was consistent over time using the subnational population estimate tables that have been created over time (Statistics NZ, 2013).

A similar approach was then taken for public libraries in New South Wales. Unfortunately, it was only possible to source data from a limited range of years and this was taken from the Public Libraries of New South Wales Directory (State Library of New 
South Wales, 1983, 1988, 1999, 2010, 2013). The 104 libraries in NSW were divided into 52 large and 52 small libraries using data from the last Australian census (Australian Bureau of Statistics, 2011). This was then checked against historical data to check that that the ranking remained constant over time (using information from Australian Bureau of Statistics, 1981). Though there was movement within the rankings, this did not effect the cut-off point between large and small libraries.

However, a more difficult problem was caused by the fact that many of the library systems in NSW are funded by multiple different councils (rather than there being a oneto-one correlation as there is in New Zealand). Therefore population figures for these councils had to be combined to get a population figure for each library system. Complications arising from this situation are discussed at in the discussion section below. The cut-off between the different sizes of library was higher than in the New Zealand case, with large libraries being those with over 47,000 in the population served.

It could be argued that the cut-off point for large libraries between the two countries should have be kept constant between the two countries, but it was decided that it would be better that each dataset was divided evenly (otherwise there would've been far more large libraries than small libraries in NSW). The possible implications of this are also investigated in the discussion section below. Lastly, there were some councils that broke off from these library conglomerations to form their own libraries and this increased the amount of small libraries over time. The data was adjusted to keep the number of large and small libraries roughly even at each point in time.

When it came to New Zealand tertiary libraries, it was decided that it was not realistic to divide them by size since there were so few of them in the first place. However, the tertiary institutions were divided by type - universities, polytechs, and teacher's colleges. The difference in the size of local tertiary institutions often reflects a corresponding difference in the type of institution - i.e., large institutions are often universities, while smaller ones are often polytechs. Therefore this seems a more appropriate division to examine within a local context and should still provide interesting evidence on how the type of institution effects the ratio of female library directors.

\section{Results}

The results of the current study are shown in Tables One, Two, and Three (shown at the end of the results section). This data is summarized in Figures One, Two, and Three. 




Figure One. The overall percentage of female managers across the different library types within New Zealand examined in the current study.

The overall results in Figure One show that the percentage of female managers is reasonably well-matched to the population of library workers overall and remains close to $80 \%$ across the period that was examined. There is some indication of an increase over time, but given the general variability within the data, this effect may not be significant.

However, the results in Figures Two give a more complex picture of gender ratios within the management of New Zealand public libraries.

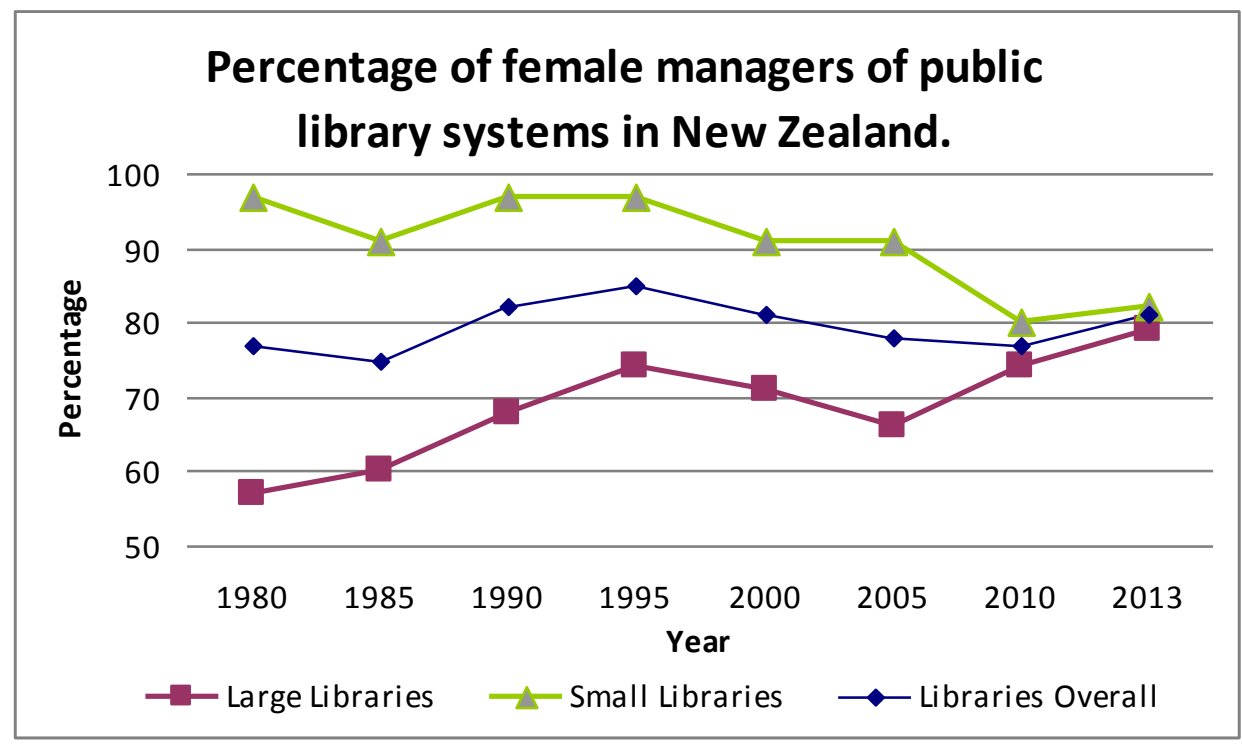

Figure Two. New Zealand results showing the percentage of female managers in charge of a public library system, shown as an overall figure and divided into large and small library systems. 
Figure Two shows that the overall percentage of female managers within public libraries also remains constant around $80 \%$. However when these libraries are divided into two groups by size, an interesting result emerges - the percentage of female district managers in charge of large libraries starts below just above 50\% then increases over time, while in smaller libraries the percentage begins near 100\% then gradually decreases. In both cases, the percentage eventually tends toward $80 \%$ female.

However, there does seem to be a sudden move against this trend in the figure for large libraries in 2005. There is no discernible reason for this slight dip, so it may be due to the natural variability within a reasonably small dataset. The results seem to suggest that when the public libraries are taken as a whole, the trends in the small and large libraries balance out and this leads the overall figure to stay near $80 \%$ across the time period.

In 2010, there was an abrupt change to some of the largest library systems in the country, when the seven libraries in the Auckland area were merged into a single library at the end of the year (after the directory for 2010 was created, which was used for this research). The resulting head management role (Manager Libraries and Information) was given to a woman, so this would have an impact on the percentage of female library managers overall. However, even if the appointment had gone to a man rather than a woman then it would only change the percentage of women managers from $79 \%$ down to $75 \%$, so it wouldn't have effected the overall trend that has been shown here (since this would still have been a rise from the 2010 figure of $74 \%$ ).

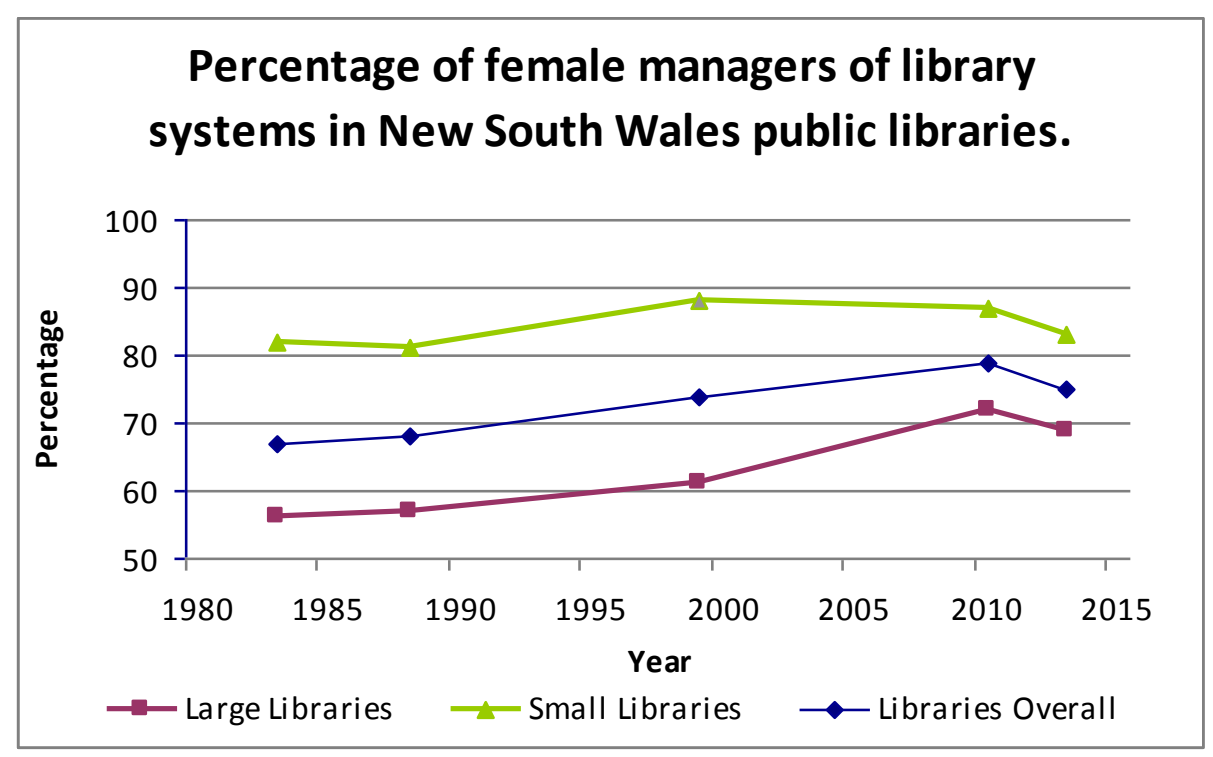

Figure Three. New South Wales results showing the percentage of female managers of library systems, shown as an overall figure and divided into large and small library systems. 
Figure Three shows comparable information from New South Wales in Australia. Unfortunately the directories were only available for a limited number of years $(1983,1988$, 1999, 2010, and 2013) so the results do not cover the time period as extensively as the New Zealand results. Nonetheless, the division into large and small library systems once again has an important part to play in understanding the data. The overall results show a possible rise in the percentage of female library managers over the years surveyed. Closer examination reveals that most of the change seems to have occurred in large library systems, which have moved from 55\% female managers in 1983 to $67 \%$ in 2013 . Meanwhile, the gender ratios of managers within smaller libraries has remained more constant, with over $80 \%$ female managers in each year that was examined. The general trend seems similar to the New Zealand data, with one of the main differences being that the percentages for large and small libraries haven't yet converged on the same figure.

No explanation could be found for the apparent drop-off in female managers shown in both large and small libraries in the final year studied (2013). It may be that random variation is at play, since the drop is just a few percentage points in both cases. More libraries went into the dataset in the NSW case, so a more reliable result would be expected. However, it was the case that there was some change in the make-up of the set of small libraries over time and this issue is discussed further below.

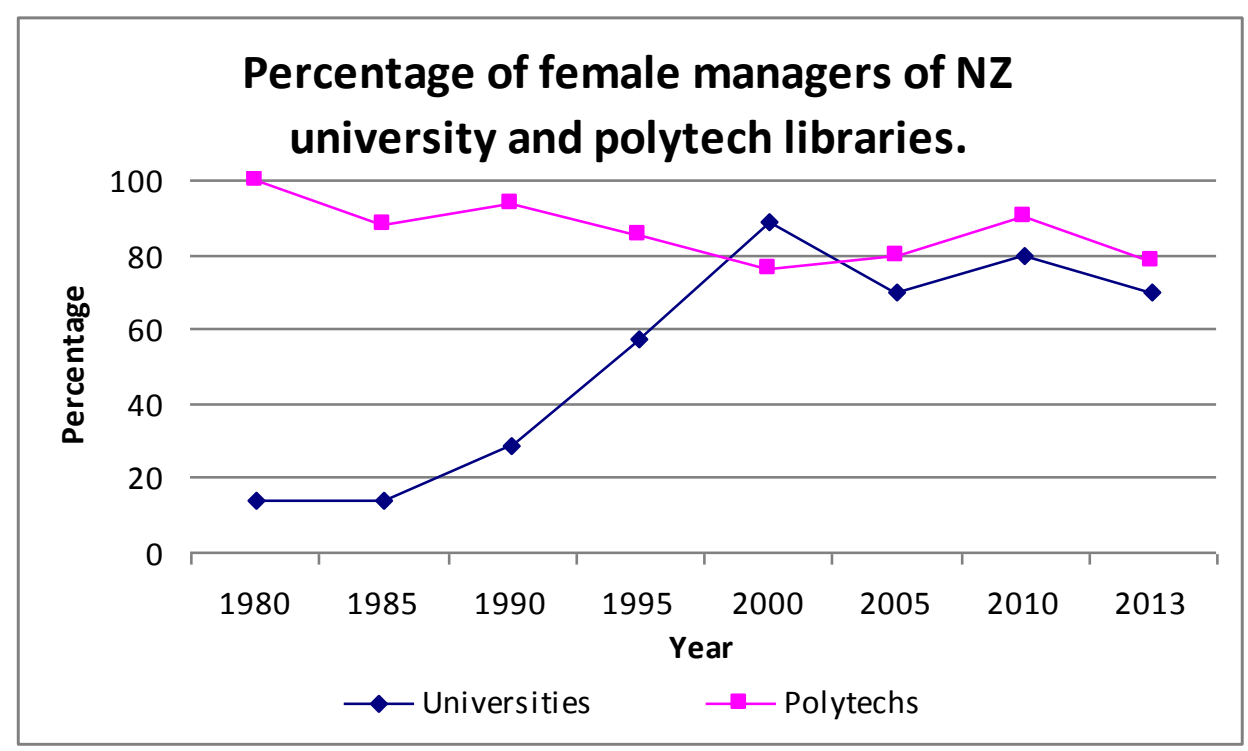

Figure Four. New Zealand results showing the percentage of female managers in charge of university and polytech libraries.

Figure Four shows the New Zealand data for polytech and university libraries over time and, on first glance, appears to show a striking result. The top management roles for 
polytechs across the country were held solely by women in 1980, but men have entered into the field since then. Meanwhile, the university libraries had a far higher percentage of male managers in 1980, but now the percentage of women managers matches the gender balance in the wider library workforce. These results fit well with the findings of Moran, Leonard, and Zellers:

- Their 1982 results showed 13\% female directors; while the closest figure from the current results is for 1980 and shows $14 \%$ female managers

- Their 1994 results showed 39\% female directors, while the current results for 1995 found 57\% female managers (which matches more closely with Fisher's 1994 data that showed $56 \%$ female directors within university libraries)

- Their 2004 results showed 67\% female directors, while the current results for 2005 found $70 \%$ female managers

The most important fact to note is the general trend that is observed in both cases, with vast increases in the number of library managers over the three decades that were examined.

However, it is essential when looking at the current results for university libraries to keep in mind that the numbers involved are very small. For example, the percentages calculated for the years 1980 and 1985 only reflect the management of seven library systems (though some might still find it striking that only one manager out of seven was female during these two years, especially if our expectation is for there to be at least $80 \%$ women). The dataset of polytechs was larger (ranging between 12 and 20 institutions), though the apparent fall in female managers over time may simply be due to natural variation. It is therefore more conservative to simply state that the percentage of female library managers of polytechs has remained high over time (remaining near or above the gender balance of overall library staff population).

It is worth noting that the size of the dataset for polytech and college of education libraries was effected by the fact that a number of polytechs and colleges of education were absorbed into universities and one polytech became a university. Wellington Polytech became a campus of Massey University in 1999 and Auckland Institute of Technology (AIT) became Auckland University of Technology (AUT) in 2000. These institutions were therefore moved across within the data during the years in which they altered their status (decreasing the amount of polytechs and increasing the amount of universities). 
The small dataset of teacher's colleges was very limited to begin with (starting with only five libraries) and, though the amount grew over time, many of these institutions were eventually amalgamated into universities. The result of having such a small dataset was that the figures collected were highly variable (see Table One).

Lastly an attempt was made to look at research libraries within New Zealand - i.e., libraries which primarily hold 'not for loan' items and which essentially exist as archives. It was hoped that these results might show an interesting difference, since the role of archivist was more evenly split between the sexes in the census data from Statistics New Zealand (2006). However, this produced a dataset that was also very small and which extended across widely variant types of library - for example, this group included the Hocken Library (run by Otago University), the National Library (run by the Internal Affairs government department), and three separate museum libraries. Our previous results would lead us to predict different trends in these different libraries (e.g., the Hocken Library might follow the trend shown by the university libraries and the National Library might follow the trend of the public libraries). This may help explain why the results for research libraries ended up being too variable to summarise (see Table One).

As a result, both the teacher's college and research libraries data was considered too inconsequential to be worth showing in a graph or analyzing in any depth. Nonetheless, the data increased the numbers used to calculate the figure for libraries overall.

\section{Discussion}

Overall, the results over both sets of data seem striking, but before any conclusions are drawn from them, it is worthwhile to consider them more deeply.

There were years in which the name listed as 'library manager' for some organizations was actually just an 'acting manager' rather than someone that held a permanent position, though this only effected a few data-points. In these cases, the gender of the acting manager was nonetheless included in the collected results.

Unlike in Fisher's (1997) study, there was not an issue with working out the gender of the person named in each listing because the source documents often listed both first and second names or, in the early years, a title was usually given with unclear names (Mr, Mrs, Miss, or Ms). In such a small country, it was also possible to find more information about a certain manager over the internet since they often continued on in libraries and could be found listed at their current job or on job-related websites (e.g., Linkedin). In the end, there 
were no cases in which a name was listed which could not be assigned a gender.

When looking at the results, it is worth noting that if the totals for female and male managers for large or small libraries fell below 35 for a particular year then this was due to missing entries. This wasn't a particular problem with the New Zealand data and, looking at Table One, it is clear that there were only ever a couple of missing entries in each category in any particular year. Though, as we shall see, this was more of a potential problem in the NSW data.

One of obvious limitation with some of the New Zealand data was the small size of the dataset, especially in the case of universities. Despite the small numbers, the data remains descriptive since it does reflect the entire range of libraries in each category, rather than being a sample which we are using to try to infer a larger picture. However, this is a limitation when it comes to considering whether these results might have anything to offer to the international conversation on gender ratios in library management. The results regarding public libraries do seem to fit well with Fisher's findings, but the small amount of universities within New Zealand make it hard to make any comparison on this account. Indeed, there are certainly not enough to divide into large and small university libraries.

While the results for the public libraries seems to show a clear trend that needs little further interpretation with statistics, it is harder to judge what can be said for certain about the university data. It is therefore useful to undertake a basic statistical test to examine how significant the university results are. If a Chi-Squared Goodness of Fit test is applied to the university data for $1980 / 1985$, then a prediction for $80 \%$ female managers can be rejected with $95 \%$ confidence. In contrast, the figures for 2013 would not reject a prediction of $80 \%$ female managers, even with a degree of confidence of $95 \%$. These results therefore provide strong evidence of a difference between the amount of female managers in university libraries in 1980/1985 and 2013. Nonetheless, the gradual rise over time shown in Figure Three may be overstating the overall trend, since a small amount of variability could have easily changed these results (i.e., just one or two managers being replaced by someone of the opposite sex would've had a remarkable impact on the results). It is better to say that our results for 1980 firmly went against the prediction that there would be $80 \%$ female managers, but that by 2013 , this prediction could no longer be rejected.

The information gathered from the directories of public libraries in New South Wales provided a larger dataset than that gathered for NZ public libraries. Once again, determining whether each manager listed was male or female didn't cause a problem since each was listed as $\mathrm{Mr} / \mathrm{Ms} / \mathrm{Mrs}$ in the directories if their name could be used by both 
sexes.

However, there was a potential issue with the change in the make-up of the libraries over time and number of blank entries given in the directories. Examining Table One, it is easy to see that the total number of library managers counted (adding the totals for females and males) always fell short of the number of libraries overall (104).

One reason for this was that there was larger number of blank entries given than in the New Zealand directories. The library manager field in the library description was often left blank, since no name had been supplied - perhaps because the position was in the process of being filled or simply because the library in question hadn't supplied the information. In the earliest year studied (1983), over a dozen libraries were listed with no manager named, whereas the New Zealand data only ever had a couple of blank entries per year. This is a sizable proportion of the NSW dataset as a whole, though there is no reason to think that the libraries with no manager listing would be more/less likely to go against the overall trend and hence influence the current results. It is also worth noting that a higher majority of blank entries were given in the small libraries rather than the large libraries, so the totals for the large libraries remain higher in each year (despite the fact that the size categories were created by dividing the dataset in half).

Another complication with the NSW results was the fact that most public library systems were funded by multiple councils. These groupings changed slightly in each of the years surveyed and so it was necessary to re-divide the libraries into large and small for each year that was studied. For example, if we look at the 1983 information in Table Two, we can see that the column for "Total" first gives the number of libraries that were included in the count and then gives the number of libraries that were listed in the directory over all (even those that gave blank entries). We can see that in 1983, there were only 90 libraries overall and that only 77 of them had entries for their library manager.

There was a gradual increase in the number of libraries over time and this seemed to be due to individual councils separating their libraries off from larger conglomerations to form their own library systems, thereby creating more smaller libraries.

In order to check whether these changes had a bearing on the overall result, another calculation was made that split the large and small libraries depending on the number of entries that were given each year. For example, in 1983 there were 77 entries overall, so the results were re-divided to reflect only the libraries that had entries for library manager, thereby meaning that the results were divided into 39 large libraries and 38 small libraries. The adjusted results are shown in Table Three. The general trend remains the same within these new calculations, with small libraries having a large percentage of female managers 
over time, while large libraries start out with a lower percentage, but this increases over time. However, the adjustment does slightly flatten the perceived trend, with the percentage being slightly higher for large libraries and slightly lower for small libraries. Nonetheless, it is not enough of a shift to conclude that the blank entries had a significant effect on the overall result.

It is worth comparing the NSW public library data to that found in New Zealand. In NSW, there was also a high proportion of female managers found in small libraries across the period studied, while the large libraries started out with a low percentage of female managers but this gradually rose over time. The overall percentage of female library managers also increased over time, but didn't quite manage to reach the $80 \%$ benchmark that would suggest that the gender imbalance had been removed (though the 2010 figure was close). In comparison, the overall total for New Zealand public libraries was near $80 \%$ throughout the period studied and only showed a slight indication of an increase over time.

There are two possible explanations for this difference between the two countries. Firstly, the smaller dataset provided by New Zealand public libraries might have been sufficiently variable that it masked the slow increase that was actually occurring over time. It is certainly true that there was an increase from 1980 (when there were $73 \%$ female managers) to 2013 (when there 83\% female managers).

Another explanation is that the difference in results from the fact that New South Wales has a larger population than New Zealand. This is backed up by looking at the current data from the 1990s and comparing this to the previously quoted study from the US carried out by Fisher (1997), which was another scale of magnitude larger. The majority of the public libraries from New Zealand and New South Wales within the current study served populations that would've put them within Fisher's small and medium categories, while only a few would've been medium-large or large sized.

Fisher's (1997) figure for the percentage of female managers of public library systems in the US in 1994 was 73\%, while the current study found 85\% in 1995. It is also true that the cut-off was higher between large and small libraries within the NSW data (large libraries served a population over 47,000) than in the New Zealand case (large libraries served a population over 39,000). Perhaps the size issue worked in tandem with the fact that there are more public libraries in NSW and hence a larger pool of experienced managers competing for the top jobs. These jobs might therefore be seen as higher positions overall and therefore the glass ceiling may be slower in retracting upward - thus delaying the slow creep towards gender balance at a management level.

Looking over the methodology and results as a whole, it is clear that the data from 
within New Zealand has been collected in a more precise and straight-forward manner, while the NSW data introduced a number of complications that could've effected the overall result. Table Three does suggest that the number of blank entries may not have been an issue, but the changing numbers of libraries over time does seem like a factor that may have altered the results. The results from NSW should therefore be considered as a preliminary investigation, which suggests a correspondence with the trend seen in New Zealand, but which still requires more follow-up research. 
Table One - Absolute figures for numbers of female and male managers across New Zealand Large and Small Public Libraries (and combined), Polytechs and Universities.

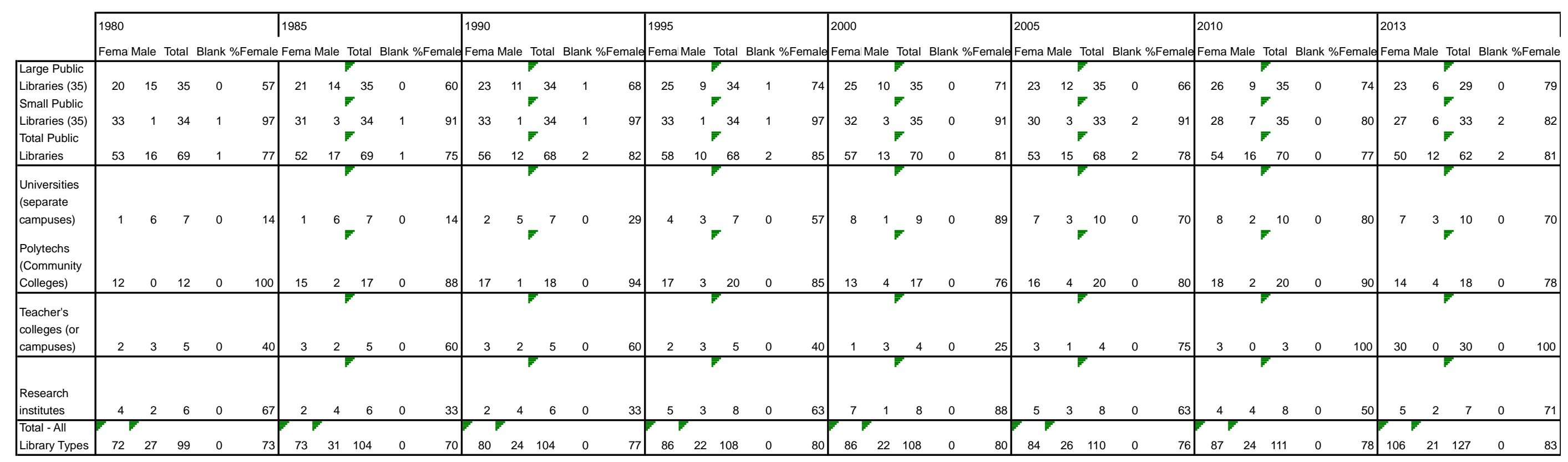

Table Two - Absolute figures for numbers of female and male managers across New South Wales Large and Small Public Libraries (and combined).

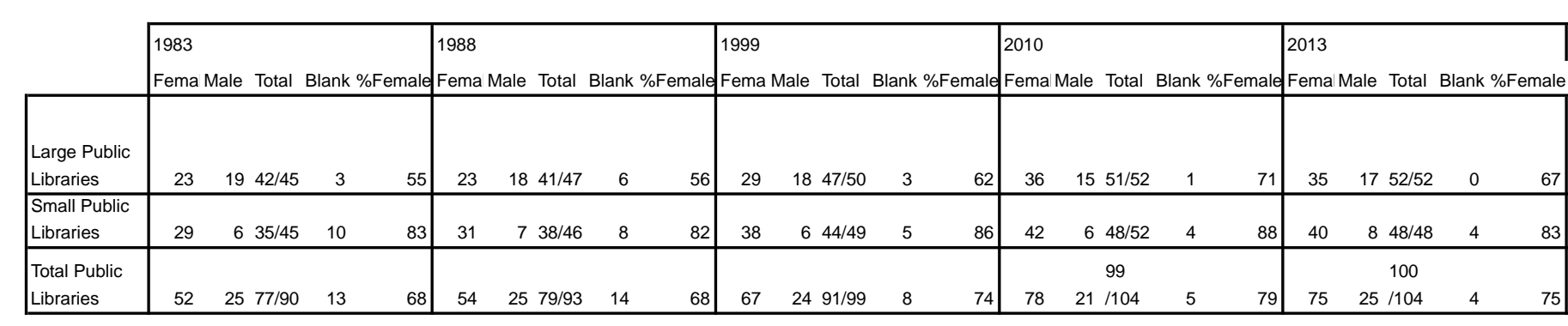

Table Three - Absolute figures counting only non-blank entries for numbers of female and male managers across New South Wales Large and Small Public Libraries (and combined).

\begin{tabular}{|c|c|c|c|c|c|c|}
\hline & & 1988 & 1999 & & & \\
\hline & Fema Male Total \% \%ern & & & & Fema Male Total & IFema Male Total \%Female \\
\hline 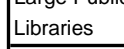 & $22 \quad 17 \quad 39 \quad 56$ & $22 \quad 18 \quad 40 \quad 55$ & 29 & $\begin{array}{lll}17 & 46 & 63\end{array}$ & $\begin{array}{ll}36 & 14 \\
\end{array}$ & $\begin{array}{lll}34 & 16 & 50\end{array}$ \\
\hline $\begin{array}{l}\text { Manipu } \\
\text { Libranes } \\
\end{array}$ & $\begin{array}{llll}30 & 8 & 38 & 79 \\
\end{array}$ & $\begin{array}{llll}32 & 7 & 39 & 82\end{array}$ & 38 & $\begin{array}{lll}7 & 45 & 84\end{array}$ & $42 \quad 7$ & $\begin{array}{lll}41 & 9 & 50\end{array}$ \\
\hline $\begin{array}{l}\text { Totala Pubbic } \\
\text { Libranies }\end{array}$ & $\begin{array}{llll}52 & 25 & 77 & 68\end{array}$ & $\begin{array}{llll}54 & 25 & 79 & 68\end{array}$ & 67 & $24 \quad 91 \quad 74 \mid$ & $\begin{array}{ll}78 & 21 \\
\end{array}$ & $\begin{array}{lll}75 & 25 & 100\end{array}$ \\
\hline
\end{tabular}




\section{Conclusion}

This research suggests that the overall gender balance of managers in charge of New Zealand library systems over the years from 1980 to 2013 has shown a slight increase, eventually reaching close to $80 \%$ female and thereby moving closer to the gender balance of the overall workforce.

However, when the public libraries were divided into large and small categories (depending on the population size that their related council served), then a slightly different trend was observed. The large libraries only had 59\% female managers in 1980, while the small libraries had $94 \%$ female managers. However, both these figures gradually moved toward $80 \%$ across the time period that was examined. The current finding for 1995 matched up well with the 1994 US data reported by Fisher (1997), who showed that larger library systems generally had fewer female directors (though his study was not longitudinal). In contrast, the current study was able to show that this difference between large and small libraries actually diminished over time and became negligible by the time of the latest data point.

The results for tertiary institutions were also striking, though hampered by the small datasets that were available. Polytechs had a proportion of female library managers that was higher than the gender balance in the wider workforce across the period studied, though there was possibly a slight decline over time. In contrast, at the beginning of the same period, university libraries had very few female managers (only one out of seven in 1980/85), but this situation was markedly changed by 2013 (with seven out of ten managers being female). However, the results for teacher's colleges and research libraries were too variable to be summarised.

There is a way in which the results that were found for public libraries might help explain the results for polytechs and university libraries. In the past, there was a clear relationship between the size of a public library system and the likelihood it had a female manager (the smaller it was, the more likely it would have a female manager). Polytechs also had a high number of female managers in the 1980s and many of these organizations were rather small (often with single branches and, even today, only a couple of polytechs have more than one library). In contrast, most of the head librarians of university libraries at this time would've overseen multiple subject libraries. In this way, the larger size of university library systems might help explain why the early polytech and university results differed so greatly. If this was the case then it would provide more proof that there was a 
glass ceiling that made it difficult for female librarians to take the top management role within the large libraries at this time, though this effect has gradually faded over time. It may be worthwhile for further research to investigate tertiary libraries in more depth, by looking at the heads of separate subject libraries and taking into account the size of the collection within each individual library (across both university and polytech libraries).

Taken as a whole, the results within the current study show a gradual improvement in the place of women within library management in New Zealand. Women were not proportionally represented within the management of large public library systems at the start of the study and only one was given the head role at a university library. However, the data from this year (2013) show that this situation has been largely rectified and female managers are spread evenly through the various types of library and at a ratio that is close to the $86 \%$ gender ratio in general library population (Statistics NZ, 2006).

What this represents is the fact that the glass ceiling has slowly been pushed upward over time, as women gained a greater proportion of the jobs at higher and higher levels, until the glass ceiling within New Zealand libraries has been almost entirely removed. This is a healthy situation for the profession since it means that female staff may be more motivated to push themselves up through the ranks, in the knowledge that they have as good a chance of advancement as their male colleagues. Hopefully this will gradually result in a workforce that is more ambitious in their career goals, which should have a positive effect on the library profession in New Zealand as a whole.

The findings from public libraries in New South Wales provided a similar picture, though the increase in the percentage of female managers was slower than in the New Zealand case and fell short of $80 \%$ even in the latter years (though came close in 2010). It was proposed that the difference between the two countries was due to their difference in size. However, it is acknowledged that the NSW data should just be considered a preliminary investigation since the complexities of how multiple councils funded each library system meant that the picture was less clear than in the New Zealand case (in which there has always been the same direct one-to-one correspondence between each library system and it's associated council).

It is nonetheless striking that the general result was so similar between New Zealand and New South Wales. This suggests that the findings for public libraries might be applicable in other overseas contexts. It would be worthwhile if this approach could be applied more extensively to data from Australia (creating a more thorough picture of the situation in NSW and providing evidence from other states across the country). A similar study could also be conducted in the UK or Fisher's original study could be replicated 
within the US.

Within New Zealand, this same source of data could be used to investigate other issues. For example, professional libraries (such as law libraries) or government department libraries could be examined to see how their gender ratios have changed over the same period (though the numbers would be relatively small since there would only be around a dozen). Alternatively, the public library data from year-to-year could be analysed to see how many managers have switched position over each five-year period (even between difference varieties of library). This would give a sense of how mobile the local workforce is at the management level (though it wouldn't feed directly into the current research on gender equality).

The current study might also be used as the starting point for further research into the changing nature of gender bias within New Zealand libraries. For example, it would be interesting if qualitative research was done into how female staff themselves have perceived the change in management structure over the same period (from 1980 to the present). One approach would be to interview library workers who have been in the field throughout these three decades to see if they have perceived changes to the way in which female managers are perceived and whether they sensed an improvement in the opportunities for women.

Looking back at the previous research on the glass ceiling in libraries, it seems that childrearing is often seen as having a large impact on women's careers. Therefore it may be interesting to see if the improvements in the numbers of female managers shown in the current study could be related to improvements in how taking time off for having children is handled in the New Zealand. During the early years of the current study period, the first laws around maternity leave were just beginning to be introduced. Job protection for mothers leaving to have children was passed in the early 80 s and this was followed by the Parental Leave and Employment Protection Act 1987, which officially allowed women and their spouses/ partners to take unpaid leave from their jobs (Ministry of business, Innovation, and Employment, 2006). 2002 saw the introduction of 12 weeks paid parental leave and this was extended to 14 weeks in 2004 and there was a relaxation of eligibility criteria. These changes may have made it successively easier for women to balance their careers and their home-life, thereby contributing to lifting of the glass ceiling within libraries, which has been shown in the current study. In comparison, Australia introduced unpaid maternity leave earlier (in 1979), but only introduced paid parental leave in 2011 (Australian Institute of Studies, 2013). This could provide another reason for the difference in results between the two countries. 
The impact of childrearing on the library profession in New Zealand has been discussed in a recent LIANZA conference paper (Anderson, 2011). This brief paper argued that childrearing has a stronger effect on librarianship because it is a "female dominated profession." An example is given from Tauranga City Libraries, where only $20 \%$ of the staff who went on maternity leave over a ten-year period returned to full-time work afterward. This may suggest that the balance between childrearing and career is still an issue that needs to be addressed. Perhaps addressing this issue will allow the percentage of female managers to climb the final percentage points necessary to reach the $86 \%$ figure found in the library workforce (as shown by the last census, Statistics NZ, 2006) and also might help close $4 \%$ salary gap between male and female members of LIANZA (as shown by LIANZA, 2010).

Nonetheless, the overall finding of the current study is a positive one. The results show that gender ratios in library management within New Zealand have now come close to matching the ratio found in the general library worker population. In the 1980s, it may have been possible to argue that there was a 'glass ceiling' keeping women from management roles running larger library systems, but this situation has improved over time to where there is no longer a difference between the gender ratios in management of small and large libraries and the overall gender balance is similar to the workforce as a whole. 


\section{References}

Anderson, M. (2011). The power of choice: Problems with a female dominated profession. Retrieved on 15 October 2013 from, http://www.lianza.org.nz/resources/conference-proceedings/2011/power-choice--problems-female-dominated-profession

Australian Bureau of Statistics (1981). Census of population and housing, 30 June 1981: Persons and dwellings in local government areas and urban centres; New South Wales. Retrieved on September 152013 from, http://www.ausstats.abs.gov.au/ausstats/free.nsf/0/21168A9CEE54C9CECA25758 3001154AE/\$File/24010 1981 PD LGA NSW.pdf

Australian Bureau of Statistics (2004). Public libraries Australia 2033-2004. Retrieved on September 152013 from, http://www.ausstats.abs.gov.au/ausstats/subscriber.nsf/0/DD3BEA2E4FA5DA11C A256FF100787DE0/\$File/85610 2003-04.pdf

Australian Bureau of Statistics (2011). Census 2011. Retrieved on September 152013 from,http://www.abs.gov.au/websitedbs/censushome.nsf/home/data?opendocume nt\&navpos $=200$

Australian Institute of Studies (2013). A short history of Australia's family leave policies. Retrieved on October 152013 from, http://www.aifs.gov.au/cfca/pubs/papers/a143831/03.html

Beveridge, Weber, and Beveridge (2009). Librarians in the U.S. from 1880-2009. Retrieved on 17 August, 2013 from, http://blog.oup.com/2011/06/librarian-census/

Currie, G. (1992). A nice job for a lady: industrial issues for librarians in the '90s. Libraries: The Heart of the Matter, Proceedings of the Australian Library and Information Association, 2nd Biennial Conference, ALIA, ACT.

Davis, D., \& Hall, T. (2007). Diversity counts. Chicago: American Libraries Association. Retrieved on May 1, 2013, from 
http://www.ala.org/ala/aboutala/offices/diversity/diversitycounts/diversitycounts rev $\underline{0 . p d f}$

Deyrup, M. (2004). Is the revolution over? Gender, economic, and professional parity in academic library leadership positions. College \& Research Libraries 65(3), 242-50. Retrieved on 17 August, 2013 from, Library Literature and Information Science Fulltext database.

Fisher, W (1997). The question of gender in library management, Library Administration \& Management, 11(4), 231-6.

Freeman, S.J. (1990). Corporate women and social change. Amherst, MA, US: University of Massachusetts Press.

Grant Thornton International (2013). Women in senior management roles - gloom gathers below glass. Retrieved on 25 May, 2013, from, http://www.grantthornton.co.nz/Press/women-in-senior-management-roles.html

Harley, S (2011). The glass escalator: male career paths in NZ libraries. (Unpublished MLIS research project, Victoria University of Wellington, 2007). Retrieved on 11 August, 2012, from, http://researcharchive.vuw.ac.nz/bitstream/handle/10063/2353/paper.pdf?sequenc $\underline{e=1}$

Jones, E. and Oppenheim, C. (2002). Glass ceiling issues in the UK library profession. Journal of librarianship and information science, 34(2), 114.

Maatta, S. L. (2011). The long wait. Library Journal, 136(16), 20-27.

LIANZA (2010). Renumeration survey 2010. Retrieved on 11 October, 2013, from, http://www.lianza.org.nz/resources/lianza-documents/remunerationsurveys/remuneration-survey-2010-results

Ministry of Business, Innovation and Employment (2006). Parental leave in New Zealand 2005/2006 evaluation. Retrieved on 17 August, 2013 from, 
http://www.dol.govt.nz/publications/research/parental-leave/parental-leave 04.asp

Moran, B, Leonard, E, and Zellers, J (2009). Women administrators in academic libraries: Three decades of change. Library Trends, 58(2), 215-228. Retrieved on 17 August, 2013 from, Library Literature and Information Science Fulltext database.

National Equal Opportunities Network (2012). NZ Census of Women's Participation 2010. Retrieved on August 13, 2013, from, http://www.neon.org.nz/census2010/teachers/

National Library of New Zealand (2013). Directory of New Zealand libraries. Retrieved on 13 July, 2013, from, http://directory.natlib.govt.nz/library-symbols-web/

National Library of New Zealand $(2000,2005)$. New Zealand library symbols. Wellington: National Library of New Zealand.

New South Wales Department of Premier and Cabinet (2002). Crown employees (librarians, library officers and archivists) interim award. Retrieved on 14 September, 2013 from http://www.dpc.nsw.gov.au/announcements/circulars/2002/c2002-12

New Zealand Library Association (1980, 1985, 1990). Who's who in New Zealand libraries. Wellington: New Zealand Library Association.

Owens, I (2009). Documenting diversity among working LIS graduates. Library Trends, 58(2), 192-214,317,319. Retrieved on 17 August, 2013 from, Library Literature and Information Science Fulltext database.

Simon, J. (1996). The "double-glazed glass ceiling" in Australian libraries. Librarian Career Development, 4, 4-14. Retrieved on 14 September 2013 from, Emerald database.

State Library of New South Wales (1983, 1988, 1999). Public libraries in New South Wales: a directory. Sydney: The Dept.

State Library of New South Wales (2010). Public libraries in New South Wales: Directory 
2010. Retrieved on 1 September, 2013 from,

http://www.sl.nsw.gov.au/services/public libraries/publications/docs/pl directory 2 010.pdf

State Library of New South Wales (2013). Public libraries in New South Wales: Directory 2013. Retrieved on 1 September, 2013 from, http://www.sl.nsw.gov.au/services/public libraries/docs/pl directory.pdf

Statistics NZ (2005). Focusing on women. Retrieved on 17 October, 2012 from, http://www.stats.govt.nz/browse for stats/people and communities/women/focusi ng-on-women.aspx

Statistics NZ (.2006). Census of population and dwelling data package. Retrieved on 15 Jun 2013 from, http://www.stats.govt.nz/browse for stats/education and training/Tertiary\%20edu cation/unistats/products-and-services/census-of-pop-and-dwellings-datapackage/module-06.aspx

Statistics NZ (2013). Estimates and projections. Retrieved on 17 October, 2012 from, http://www.stats.govt.nz/browse for stats/population/estimates and projections.a spx\#estimates

Strong, C. (2011). Female journalists in New Zealand daily newspapers: From early career to gender gap in editorship. Massey University (Doctorial Thesis), p. 1-319. Retrieved on 6 October 2013 from, http://mro.massey.ac.nz/bitstream/handle/10179/2780/02 whole.pdf?sequence=1

US Department of Labor (2011). Good for business: Making full use of the nation's human capital. Retrieved on 17 May, 2013 from, http://www.dol.gov/oasam/programs/history/reich/reports/ceiling1.pdf

Williams, C. (1992). The glass escalator: Hidden advantages for men in the "female" professions. Social Problems, 39(3), 253-267. Retrieved on 17 August, 2013 from, Library Literature and Information Science Fulltext database. 
Zemon, M., \& Bahr, A. H. (2005). Career and/or children: Do female academic librarians pay a price for motherhood? College \& Research Libraries, 66(5), 394-404. Retrieved on 14 September 2013 from, Emerald database. 


\section{Gareth Shute}

INFO 580, Report 